\title{
Online Student Publishing in the Classroom: The Experience of the Michigan Policy Network
}

Matt Grossmann, Michigan State University

ABSTRACT In this article, I describe my work with Michigan State University undergraduates to produce the Michigan Policy Network, a web-based public service and research program that reports news and information about the political process surrounding Michigan state policy issues. The program empowers undergraduates to oversee website sections devoted to policy issue areas, each of which features background information, research, and current updates on government action, as well as regular blog posts, that aim to make the information accessible to a public audience. I explain how to inexpensively set up such a program and reflect on the strengths and weaknesses of the approach. I evaluate the four different methods that I have used to integrate the policy network with traditional teaching: (1) working with students as an extracurricular activity, (2) organizing a summer program for government interns acting as researchers, (3) integrating network assignments with traditional homework in topical classes, and (4) teaching a separate class for freshman honors students. My experience suggests that students are motivated to complete work intended for a public audience and are well-equipped to translate government information for public readers. Working on the policy network improves student employment prospects and helps build connections between state government and the university. I recommend that similar programs be developed elsewhere.

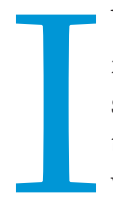

began teaching at Michigan State University (MSU) in 2007 in the midst of a battle over the state budget. By the standards of state government reporting, the budget negotiations between the governor and the legislative leaders were big news. My students knew all about the legislators who slept overnight in the capitol building while their leaders negotiated, and each one had an opinion about who was to blame for the gridlock. Unfortunately, most knew nothing about the substantive policy debates behind the disputes. Neither the students nor the public could identify the basic components of the state budget, and neither the local television news nor the local newspaper provided this information.

Yet a few students were surprisingly well informed. Because the university is located just over three miles from the state capitol, some political science undergraduates were interning at the

Matt Grossmann is an assistant professor of political science and Director of Undergraduate Studies at Michigan State University. He also serves as Director of the Michigan Policy Network. He can be reached at matt@mattg.org. state legislature during the budget crisis. These interns could recite a number of the budget items under dispute. Many spent considerable time engaging in online discussions about state government using social media sites, blogs, and discussion forums to share their views. I decided to encourage these students to spend their online time researching and reporting about state policy. Rather than sharing their knowledge only with me in a class essay, I thought they might be motivated to increase the depth of their own understanding and share what they found with the public.

One year later, working with 10 undergraduates and two other professors, I launched the Michigan Policy Network (MPN) at http://www.michiganpolicy.com. This web-based resource is a student-led online public service and research program that reports and organizes news and information about the political process surrounding Michigan state policy issues. The project empowers undergraduate students to manage website sections dedicated to policy issue areas, each featuring background information, research, and current updates on government action, as 
well as regular blog posts, to make the information accessible to a broad audience.

Three years later, more than 70 students have now written for MPN, and more than 127,00o unique website visitors have read their work. ${ }^{1}$ I use four different methods of integrating MPN and traditional teaching: (1) working with students as an extracurricular activity, (2) organizing a summer program for government interns acting as researchers, (3) integrating MPN assignments with traditional homework in topical classes, and (4) teaching a separate MPN class for freshman honors students. Along the way, I have learned a great deal about the benefits and pitfalls of publishing student assignments and integrating new media into the classroom. I see great potential in asking students to prepare materials for public use, and I am convinced that political science undergraduates can help fill some widening gaps in political reporting and research. MPN is a unique model for integrating new media into the classroom. Given the broad potential for online student publishing, others may be able to learn from our experience.

\section{STATE POLICY RESEARCH AND REPORTING}

I created MPN in response to a key democratic deficit: low public political information. Political professionals typically have access to abundant political research and reporting, and Michigan is no different in this respect. The media outlets that serve the state policy community best are two expensive subscription services and a public television news show. Michigan has a professionalized legislature, independent budget agencies, think tanks, and a civil service that advises policymakers. sample of Michigan citizens read, heard, and discussed information on Michigan policy; after the weekend, participants' opinions had become more supportive of tax increases and retirement reforms that would help balance the state budget (Center for Deliberative Democracy 2010).

The web has the potential to improve public knowledge of policy. According to regular surveys by the Pew Internet and American Life Project, every year more U.S. citizens access news and political information from the web (Rainie, Cornfield, and Horrigan 2005). Michigan citizens also use the web to find political information (Wilson 2001). Yet the vast majority of political websites focus on general commentary, whereas government websites are complex and unreadable for many citizens.

I designed the policy network because I thought that undergraduate students could help fill a void, providing online information about policy issues and translating government records to enable public understanding. Many college students are technologically adept and spend extensive time creating online content. Few professors have thus far asked students to use their online time and skills for public service. The policy network provides a productive outlet for students by leveraging their Internet expertise and policy interests for public education.

\section{CREATING AN ONLINE POLICY NETWORK}

I proposed MPN with the help of two other political scientists, Daniel Bergan and Mark Axelrod. We obtained \$10,0oo in start-up funds from MSU's Office of Outreach and Engagement and the College of Social Science, the College of Communications, and James Mad-

\section{Many college students are technologically adept and spend extensive time creating online content. Few professors have thus far asked students to use their online time and skills for public service. The policy network provides a productive outlet for students by leveraging their Internet expertise and policy interests for public education.}

In comparison, the public is not well served by the news media for policy information. In its recent survey of the state capitol press corps, the American Journalism Review found that only six reporters covered the Michigan state capitol full-time, none of whom worked for the capital city (Lansing) newspaper (Dorroh 2009). Nationwide, the survey found that the number of full-time state capitol reporters dropped from over 500 in 2003 to less than 400 in 2009.

The dearth of public political information is likely to have important consequences. Michigan has faced economic instability and a lack of political consensus for decades (Browne and VerBurg 1995). Public engagement is a missing but necessary precursor to effectively making difficult policy choices (Skocpol 2003). Many Michigan citizens voice concerns about policy outcomes and want to play a role in the political process (Hembroff and Clark 1998), but the neglect of policy coverage makes informed participation difficult.

Public opinion of the budget process offers an instructive example. Michigan citizens know little about the budget policy choices that face the state and are unwilling to endorse any cuts or raise any revenues at a level sufficient to keep the budget balanced (EPIC-MRA 2009). In a weekend deliberative exercise, however, a ison College (a residential public affairs college). We began developing the website in the summer of 2008. We had two goals for the site's technology: (1) to create separate, fully featured sections for each policy area; and (2) to enable undergraduates to easily submit materials and updates to the site. To meet these goals, we elected to use the open-source Joomla content management system, which is available without charge at http://joomla.com. Joomla is regularly updated, uses off-the-shelf templates, and offers more than 7,00o plug-in extensions to add diverse features to a website.

We hired contractors to develop graphics and build the website. The main contractor, Cory Webb, was a Joomla specialist who has written a book on the system (Webb 2009). We began building content with 10 policy area sections: agriculture, state budget, $\mathrm{K}-12$ education, employment, energy and environment, health care, morality and family, political reform, taxes, and urban affairs. In 2009, we added five additional sections: commerce and regulation, criminal justice, Great Lakes and recreation, social services and seniors, and transportation. The section titles match the names of state legislative committees and executive departments. The site includes interactive features such as article comments, discussion forums, a wiki (developed using the same software used by Wikipedia), and community profiles, as well as 
Figure 1

\section{Public View of Home Page}

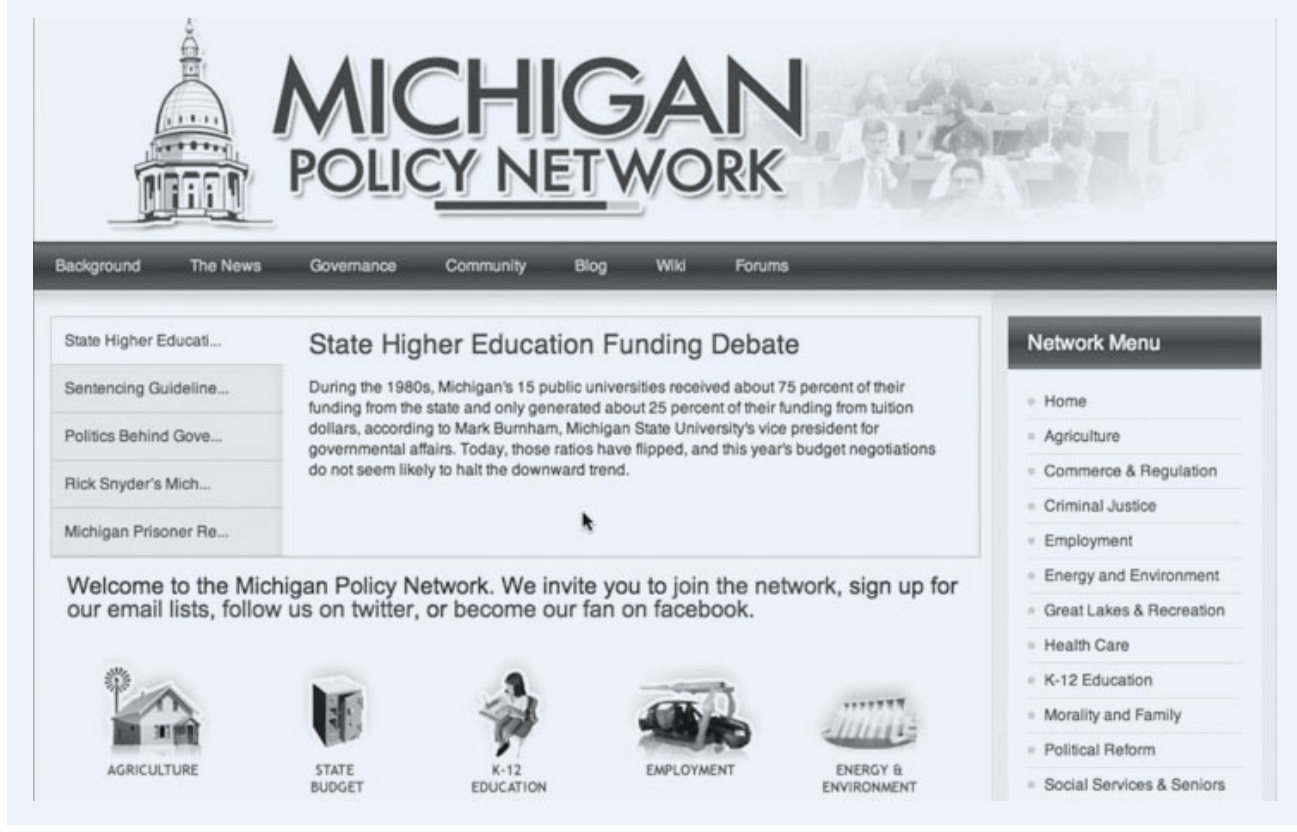

imented with articles that list the pro and con arguments used by each side, as well as pointcounterpoint commentaries written by multiple students. As students approach the end of their time writing for the site, we allow them to write commentaries and opinionated blog entries as long as they are clearly labeled as such.

The MPN is officially housed within the department of political science but is entirely virtual and requires no office space. Drs. Bergan and Axelrod and I recruited the first 10 students using e-mail solicitations and recommendations from instructors in the spring 2008 semester. We interviewed candidates and reviewed resumes and relevant academic work. In the fall 2008 semester, each student took charge of a policy area e-mail lists, Really Simple Syndication (RSS) feeds, and Facebook and Twitter accounts for users who want regular updates.

Figure 1 depicts the front page of the site. Each policy area section, listed on the right sidebar, offers diverse written content. First, students write background policy briefs that are meant to introduce visitors to a topic. Second, they collect and annotate citations and links to papers written by advocates, researchers, and government officials. In a research index, students review academic papers related to policy issues under debate in Lansing. In another index, students list and link to interest groups, institutions, legislators, and activists who are involved in the state policy debate. For each link, they indicate the ideological or issue perspective that the source represents and the role that they have played in past policy debates. On a timeline page, students create a historical record of major legislation and administrative decisions considered in the Michigan state government. In a national context area, students explain the similarities and differences between the Michigan debate and debate occurring in other states and at the federal level. In a current issues area, students list and highlight specific ongoing legislative and administrative debates within their assigned policy domain. For each issue, they summarize the current stage of the debate and the positions articulated by different sides and constituencies. A news coverage area of each section contains annotated links to news stories from other sources; this section is also automatically updated with links to external news coverage of Michigan policy. Each section further includes a commentary area, in which students cite, link to, and annotate newsletter articles, reports, blog entries, and op-eds relevant to state policy decisions. In the interviews area, students upload audio or transcripts for interviews that they conduct. Each student also has a blog on which he or she writes shorter news updates or commentaries on state policy actions.

Most student-produced content is objective. Students report events, summarize news reported elsewhere, and interview proponents and opponents of particular policies. We have also exper- that interested him or her. We connected students with an internal academic advisor from the university and an external mentor from the policy community. In the first few months of the school year, students worked to add content to all of their areas before our public launch. After the site's launch, they added regular updates and new content on a weekly basis.

Students update all areas of the website using a web-based administration system. They need no technical knowledge to participate, only a short training session. Figure 2 illustrates the webbased system for site updates. Students $\log$ in to the site and see a new menu. Then, using any web browser, they simply type and edit content in form boxes. Students can also copy and paste from word-processing software. When an article is complete, they can decide to either submit it to appear on the public version of the site instantly or save it for later editing. During their first few months working with the policy network, the system only allows students to submit their work for further editing. Site editors then use the same administrative system to review and revise student work before publication. The system also contains separate features for creating new annotated links to different types of content and adding forum posts or calendar items.

In the MPN's first three years, students have created a significant trove of content. They have written 944 articles, including policy briefs, pro-con issue analyses, reports on national context, interview transcripts, legislation summaries, and blog entries. ${ }^{2}$ Students have also contributed more than 1,20o annotated links to material available elsewhere online, including research reports, interest group websites, position papers, news stories, and editorials. Each policy section provides accessible information for nonexperts in each policy area, as well as current legislative tracking, issue news coverage, and analysis of government actions that is of interest to practitioners.

The network now receives considerable traffic. In 2008, the site attracted approximately 9,000 visits, but this number grew to over 128,00o visits in 2009 and over 235,000 visits in 2010. In 
Figure 2

\section{Student View of "Add Article" Administration Page}
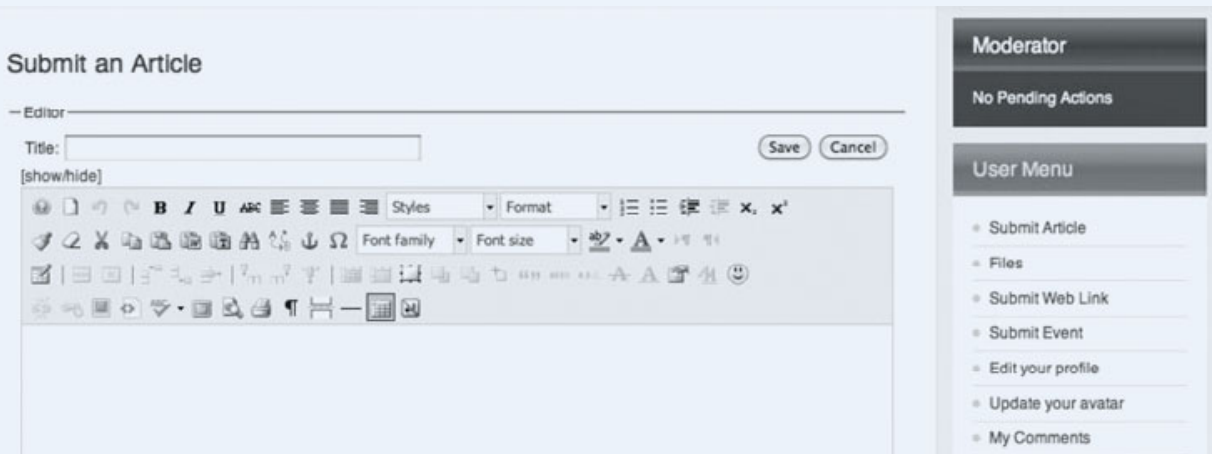

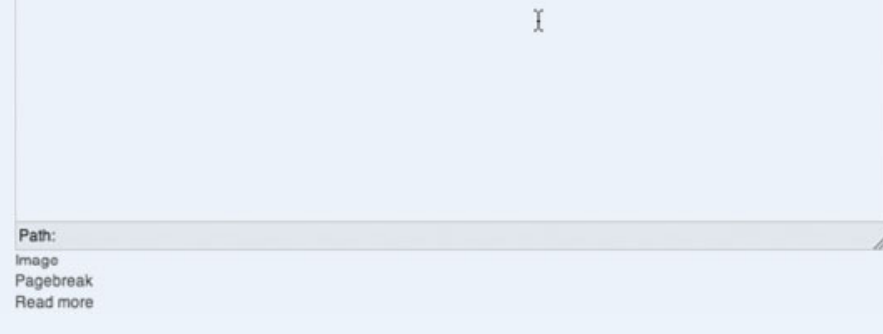

problems facing Michigan, the state policymaking process, and the important actors in Michigan government. For all three categories of information, more than half reported possessing a higher level of information on the exit survey than on the entrance survey. The survey also confirmed that students' political knowledge increased; average scores on an index of political knowledge climbed more than $25 \%$. The average number of newspaper articles read per day climbed from 19 to 24 , and the average number of government officials that the students said that they knew more than tripled. Students did not report higher levels of efficacy or trust in government, however, and were not significantly more likely to report planning to stay in Michigan or

addition to return traffic, we now average more than 200 new visitors per day. The network attracts a wide variety of users, including legislative and administrative staff, reporters, students, advocates, and interested voters. The Democratic and Republican caucuses in the state house and senate now send our news reports to all legislative offices. More than 550 users and 483 commenters have registered to post their own information on the site. We have 231 RSS feed subscribers and 304 Twitter followers. However, more than three-quarters of our traffic originates from search engines. We have appeared on more than 56,ooo different Google keyword searches. Visitors have also reached the site from links on 1,80o different websites, including blogs and news sites that link to our content. Every major search engine indexes the network's content daily, as do Google News and Yahoo News.

Education and health are the most popular sections of the site, but all of the sections have generated frequently visited articles. Our readership has a long-tail distribution: more than 6,ooo pages have been accessed by at least one reader, but fewer than 20 people have viewed the median page. The most popular pages on the site are the policy briefs and current issues articles, with the forum, wiki, and annotated link pages being less popular. Our most popular article has been accessed more than 90,ooo times. One of our articles has received 172 user comments, but most articles receive none.

MPN students have also presented their work in other forums. Twenty-five students have presented their research at the University Undergraduate Research and Arts Forum. One student appeared as a guest on a news radio program. Five students have been asked to produce additional information about the issues that they have covered for state legislative offices. Six students have credited their work on the site as a major factor in their ability to obtain a related job or internship.

Our initial student participants completed entrance and exit surveys as part of the program. The survey results indicate that students became more informed about the economic and political pursue careers in government. One student summarized his involvement positively:

This was a great experience. Everyone was helpful and kind. It developed my knowledge of Michigan politics and my issue area more than I would have done on my own. Working with web technologies was also a major bonus. Employers expect this kind of experience now. The MPN did a great job further exposing me to this.

There are several important benefits for student participants in the MPN. First, they have the opportunity to work with other students to build and manage an extensive online resource. They coordinate on the network but also have the pride of ownership associated with overseeing their own unique resource. Second, students gain firsthand knowledge of state government and the policy process. They talk to policymakers and produce original policy-relevant reports. Third, students learn the new communication, reporting, research, writing, and technical administration skills that command a premium in the job market. They exit college with experience in covering public policy debates and using web-based software to organize and promote online content.

\section{FOUR MODELS FOR INTEGRATING NEW MEDIA INTO THE CURRICULUM}

During the first three years of the MPN, I experimented with four different methods of integrating the policy network into the undergraduate curriculum. I initially ran the network as an extracurricular activity with weekly evening meetings. Subsequently, I created a summer program to accompany student internships in the state legislature. Third, I assigned MPN work in multiple classes that focused on relevant topics. Fourth, I created an honors research seminar for incoming students who were interested in state policy. All four models generated extensive content for public consumption on the web, but each had its strengths and weaknesses.

The initial model was the most costly, in terms of consumption of both faculty time and resources provided to students. 
Recruiting students and finding mentors took considerable time. I recruited participants from the College of Social Science, James Madison College, the College of Communications, and the Honors College. All students attended several information and training sessions. Work on the site was done entirely outside of the classroom. Each student participant was assigned a particular issue and placed in charge of running the section on that issue. The students and faculty involved held weekly meetings, and students also met with their internal faculty advisor and external mentor several times per semester.

I provided all student fellows with a nominal stipend for their work. These resources were drawn primarily from existing fellowship programs designed to promote student-faculty collaborative research or student civic engagement activities. These programs required students and faculty to individually apply for each of their stipends.

The rationale for offering stipends was that the money would entice students to join the project and ensure that they put effort into their work. Providing stipends, however, did not stimulate as much written material as the incentive system built into the other three models: assigning students tasks as homework in a classroom environment. The stipends did allow students to include the MPN on their résumés as work experience. Amazingly, however, none of the students who received the initial stipends reported that these funds motivated them to participate. In fact, all three original students who were not seniors continued to work on the network the next year without stipends.

Because of insufficient resources and time commitments, I discontinued the extracurricular model after the first year. Since that time, however, six students have applied and received Dean's Assistantship stipends to conduct independent work on the MPN. I have also continued to oversee the independent volunteer work of nine other students, as well as four students engaged in related independent studies. Independent work allows students to take full ownership of their role in directing the MPN but makes it more difficult for faculty and other students to provide feedback on their work and does not ensure regularity of output.

The second model for integrating the MPN with the undergraduate curriculum took advantage of our internship program. The department of political science offers internship credit to students who work in state government; the majority end up working in the legislature. Students are required to submit written materials online, but the department does not typically conduct any in-person sessions. To avoid a situation in which no new content was uploaded to the MPN throughout the summer months, I decided to offer students a more programmatic internship program involving the site. Students received credit for their internship hours and for attending a weekly three-hour evening course near the state capitol building. The program incorporated guest speakers and public debates, simulations and group activities, short lectures, and work on the policy network. A graduate of the policy network's first year served as site editor and program coordinator over the summer. Students worked on the network during the last hour of class time, using materials I provided and their own research to write short weekly blog entries, legislative summaries, and policy briefs. They also conducted two transcribed interviews outside of class.

The main benefit of associating the MPN with an internship program was that the students shared experiences and were able to rely on each other for advice and editing. The group developed camaraderie; students interjected internship experiences and their views of ongoing state legislative battles into our classroom discussions. Instead of arranging mentorships with people in the state policy community, I was able to rely on the relationships that students developed with their internship advisors and our guest speakers. Several internship program students remained involved in the MPN during the next school year, and one was offered a related job by a guest speaker. Our weekly writing sessions allowed all of the students to accomplish something each week, provide feedback on each other's work, and respond to comments from the editor.

I initially feared that internship coordinators would not appreciate their interns writing online about state government. However, none objected, and several even voiced support for students' work and went out of their way to match internship responsibilities with students' targeted policy areas. Even the students who were given mostly constituency service tasks in their internships informed me that their MPN responsibilities improved their work output and made them feel more involved with state policymaking.

The third model of integrating the MPN with the curriculum took me outside the department of political science to the Honors College. Honors students at MSU identify with the Honors College as well as another college, through which they pursue their major. In addition to their major requirements, freshman and sophomore honors students are encouraged to enroll in research or civic engagement seminars. Faculty members propose these courses, and the Honors College provides some minimal funding for the courses.

I offered an honors research seminar for incoming freshman in 2009 and another version in 2010. The seminar required students to produce materials for the site and incorporated a similar set of lectures and practicum experiences as that used in the summer internship program. The main difference between the two was that the students in the seminar were younger, more diverse in their interests, and not yet working. None of the students were political science majors; rather, they came from eight different majors. I had to modify my lessons on state policy for freshmen who knew little about government, but they were all generally fast learners. Students had easy access to relevant examples for political science theories, because each was immersed in the politics surrounding a particular policy area at the state level. Initially, the honors students took longer to become comfortable with state policy writing, but by the end of the semester, they found it easier to complete assignments. Because research seminars at MSU are designed to include one semester of coursework (three hours per week) and one semester of independent research, students completed several more self-directed projects for the network and conducted a longer investigation for presentation at the undergraduate research forum on campus in the second semester.

The final model of integrating new media into the curriculum was to assign stories and research for the MPN in traditional political science and public policy courses. I began by assigning halfhour interviews with policymakers and interest group leaders in my political parties and interest groups course. I gave the students contact information for specific individuals in the state policy community and told them that their interviews would possibly be published online on the MPN site. Most students were able to obtain permission for audio recording and public posting from their interviewees. These transcribed interviews became some of the most accessed pages of the MPN, primarily because when 
Internet users search for a person's name, these interviews appear in the search results. Several students said that the online posting of the interviews provided extra motivation for completing them.

The political science department at MSU also offers a writingintensive capstone course for graduating seniors in political science. My version of the course covers the politics of the policymaking process and incorporates three writing assignments that are often published on the policy network: a summary of current state legislation, a state policy news story, and a background brief on a state policy problem. Assigning articles that may be posted on the MPN site fits with the course theme and the university's goal of increasing student practice in writing and editing. Most students want to publish their stories under their own byline, but a few request anonymity. Several students commented that they enjoying seeing their articles online and knowing that these pieces have a substantial number of readers.

\section{UNEXPECTED STRENGTHS AND PITFALLS}

The most surprising success of the MPN has been the ease with which it gained a substantial readership. I did not anticipate several factors that made web popularity easy to achieve. First, all of the state's major newspapers archive their content, often as early as one week after a story is printed. Much of our traffic comes from users searching for information on a prominent past issue; our summaries of news reported by others often come up first in these Google searches. Second, news search engines drive considerable traffic. Since Google News and Yahoo News index the MPN regularly, we often have hundreds of readers soon after an article is posted. Third, many third-party websites automatically aggregate news stories relevant to their focus. Adding new headlines to Facebook and Twitter often yields immediate additional links from topical sites.

As a result, we do not need a continuing advertising budget. We initially purchased $\$ 2,000$ worth of advertising for the site, including ads on the Lansing newspaper website and search engine keyword advertising from Google, Yahoo, and Microsoft. According to the newspaper, our ad had the highest click-through rate ever recorded by their website. However, the advertising campaign never accounted for a large share of our visitors and no longer seems necessary.

The second surprising upside to the site has been the reaction of potential student employers. State government agencies, lobbyists, public relations firms, and political organizations employ many college graduates and are the main source of employment for political science graduates. For most students, the presence of even one article on the site with their byline ensures that the MPN will be among the first hits when potential employers search their name on Google. Because finding information about potential hires online is now a common practice, more than 15 students have reported to me that their potential employer or internship director read material that they wrote for the site. So far, all of the reactions have been positive, often because searches for other applicants' names have yielded only Facebook profiles. In addition, a large number of students who work on the MPN have used me as a reference or asked for letters of recommendation. When I have performed this task for other students unaffiliated with the MPN, I have rarely heard from employers. However, employers frequently call me directly about students who work on the MPN to discuss their work. The employers always note that my students appear to have substantial relevant experience.

Yet each of these strengths has been accompanied by an unexpected weakness. The popularity of the site means that I must be mindful of potential errors. I rely almost completely on students to edit both their own work and that of other students. A graduate student editor and I do review posts, but we do not check facts or original sources. Throughout the existence of the MPN, students have posted several errors on the site, including misattributed facts and incorrect quotations. Students also often overlook grammar and usage mistakes. As a result, we receive user corrections and complaints via e-mail and comments. We have fielded corrections from government officials, interest groups, and independent citizens. It is not difficult to correct the errors in the story, but misinformation can spread before it is corrected. The MPN has also unwittingly passed along incorrect information reported elsewhere on the web, usually in press releases, news stories, or think tank websites.

Students participating in the project also have to worry about how their reputation develops as a result of what they write for the site. Because most reports written by the students are nonpartisan summaries or news items, they typically pose little threat. Yet readers sometimes insult student authors in comments (which we later remove). The positive impact of a reputation gained from online writing can also affect students in unexpected ways. One student chose to cover a policy area that was not his primary interest. Since beginning to write for the site, all of his internship opportunities and job offers have been related to this issue, rather than others that he would like to pursue.

The final unexpected role of the MPN has been to serve as a substitute for information from the state government. Some of our readers assume that we are an apparatus of the state government, and many write to us with the same types of questions often fielded by legislators and state bureaucrats. We even generate traffic from search engine queries that contain navigational terms like "michigan.gov" and "legislature.mi.gov." Rather than contacting their legislator, many citizens now turn to Google to request government information. We initially thought that Google was misdirecting searchers in our direction. In following up on the particular search terms used by web visitors, however, we found that much of the information that users are seeking is available on our site, but not on the state government site.

\section{CONCLUSION}

I view the MPN as an opportunity for students to apply their classroom lessons to real-world politics. I also hope that students can use their computer and writing skills to improve public information about state politics and policy. Of course, undergraduates are no substitute for newspaper reporters with the state government beat. Especially in the absence of substantial editing or a large budget, students cannot replace traditional reporting or the work of government information offices.

Nevertheless, this project does fill a niche. We are the only source of publically available information in many of the policy areas that MPN covers. We are able to cover government actions that do not make the newspapers. We can also focus on the political process that determines how policy issues are resolved without the need to invoke scandals or report on election prospects. In addition, students have some advantages as interpreters of 
government: they ask the same basic questions that most of our public readers ask, and they are open to new policy ideas.

Of the four models for integrating MPN into the traditional undergraduate curriculum, I wholeheartedly endorse two: (1) assigning students to write articles for potential online publication in their topical classes, and (2) designing an internship program that offers students an outlet to learn more about state government and share their thoughts with other students and the public. The prospect of online publication appears to increase the amount of time that students spend on assignments. Using an outlet that generates hundreds of readers is more appealing to students than turning in an assignment that only a professor or teaching assistant reads.

Pairing an internship program with online publication requires more program development but is worth the cost. First, many students regard traditional internship classes as a form of paying for credit hours; they could obtain the work independently and do not perceive the university to be providing a benefit. Second, many students are disappointed that their government or political internships do not involve many political or policy-related activities. I believe that providing students with an additional role during their internships, such as summarizing policy activity around a particular issue and producing explanatory materials for the public, motivates students and encourages them to continue in their field.

I am hopeful that aspects of my experience with the MPN can help political scientists around the world pursue related projects. Most directly, many state universities in state capitals could use undergraduates' skill sets to produce material to inform the public about state government. Political science departments could also help provide online information about government and policymaking at the local and national levels. More broadly, I encourage faculty members to ask themselves whether their students are producing work that has value to the public. Simple activities like providing an archive of student papers on a particular topic or making class discussions of policy issues or debates available on public forums could prove valuable (Grossmann 2010).

Scholars are still in the early stages of using the web as an outlet for student work. The MPN offers one model for projects that integrate public information with an undergraduate curricu- lum. My experience with four different models of integration testifies to the fact that the process is not always straightforward. The variety of routes available for enabling online student publishing and using new media in the classroom, however, may turn out to be one strength of a web-based approach. Perhaps one day, many student projects will find their way to members of the public who might benefit from the skills and knowledge of political science undergraduates.

\section{NOTES}

1. I have previously described the policy network in the context of Michigan State University's efforts to interact with state government (see Grossmann 2010). Some site statistics and program descriptions from the previous article are repeated here.

2. Article and readership statistics are derived from Google Analytics software (http://analytics.google.com), Joomla's internal system for tracking article requests (http://joomla.com), and SiteGround's web management tools (http: //siteground.com).

\section{REFERENCES}

Browne, William P., and Kenneth VerBurg. 1995. Michigan Politics and Government: Facing Change in a Complex State. Lincoln: University of Nebraska Press.

Center for Deliberative Democracy. 2010. "By the People: Hard Times, Hard Choices Michigan Residents Deliberate." http://cdd.stanford.edu/polls/btp/ 2010/mi-hardtimes.pdf.

Dorroh, Jennifer. 2009. "Statehouse Exodus.” American Journalism Review April/ May. http://www.ajr.org/article.asp?id=4721.

EPIC-MRA. 2009. "Statewide Poll Report-September 2009." http://www. epicmra.com/press/Stwd_Survey_Sep2009_Media_Freq.pdf.

Grossmann, Matt. 2010. "Political Science at the State University in the State Capital." The Forum 8: Article 3.

Hembroff, Larry, and Karen Clark. 1998. "Michigan 1998: Problems and Priorities." Michigan State University Institute for Public Policy and Social Research. http://www.ippsr.msu.edu/SOSS/SOSSbriefing.asp.

Rainie, Lee, Michael Cornfield, and John Horrigan. 2005. "The Internet and Campaign 2004." Pew Internet and American Life Project. http://www.pewinternet. org/pdfs/PIP_2004_Campaign.pdf.

Skocpol, Theda. 2003. Diminished Democracy: From Membership to Management in American Civic Life. Norman: University of Oklahoma Press.

Webb, Cory. 2009. Beginning Joomla! Web Site Development. Hoboken, NJ: Wiley.

Wilson, Mark. 2001. "Internet Use in Michigan." Michigan State University Center for Urban Affairs. http://www.msu.edu/user/wilsonmm/MiInternet.htm. 